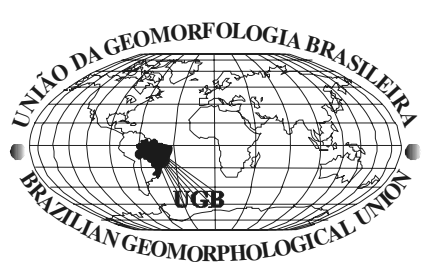

\title{
PIPING EM ÁREA DE VOÇOROCAMENTO, NOROESTE DE MINAS GERAIS
}

\author{
Cristina Helena Ribeiro Rocha Augustin \\ Instituto de Geociências - Universidade Federal de Minas Gerais (UFMG) \\ Av. Pres. Antônio Carlos, 6627, Campus Pampulha, Belo Horizonte, Minas Gerais - CEP 31.270-901 \\ chaugustin@igc.ufmg.br \\ Paulo Roberto Antunes Aranha \\ Instituto de Geociências - Universidade Federal de Minas Gerais (UFMG) \\ Av. Pres. Antônio Carlos, 6627, Campus Pampulha, Belo Horizonte, Minas Gerais - CEP 31.270-901 \\ aranha@geol.igc.ufmg.br
}

\section{Resumo}

Dutos formados por piping constituem feições erosivas sub-superficiais bastante estudadas, presentes nos mais diversos tipos de climas, sendo que a literatura específica lhes atribui participação no voçorocamento. Este artigo discute a ocorrência de quatro (4) diferentes tipos de dutos (pipes) encontrados em área de estudo localizada em Gouveia-MG, na região tropical sub-úmida do cerrado, com predomínio de latossolos, onde os piping ocorrem, em alguns casos, associados à presença de voçorocas. Estas estão presentes tanto em vertentes convexas, quanto côncavas, desenvolvidas sobre rochas granitognáissicas e básicas-metabásicas, formando um relevo ondulado a moderadamente ondulado, com declividades entre 5 e $12^{\circ}$. Os topos dessas vertentes são longos, relativamente chatos, permitindo a manutenção de colinas do tipo maciço, cujos flancos são interrompidos por reentrâncias relativamente pequenas, as quais, em alguns casos não chegam a formar anfiteatros, e esporões largos. O piping foi identificado em diferentes situações durante trabalhos de campo conduzidos na área por meio da identificação de dutos (pipes), com ou sem colapso. Eles se diferenciam em tamanho, localização na vertente, o tipo de solo e mesmo quanto à sua posição nos taludes das voçorocas. Nesse trabalho, eles são descritos e classificados com base na existência ou não de colapso do túnel e sua associação com a presença ou não de voçoroca. O colapso gera o aparecimento de um canal superficial, possibilitando que este se aprofunde e alargue, causando o desenvolvimento de voçoroca. No caso dos canais sem colapso, tem-se duas situações: piping sem a presença de voçoroca e detecção através da abertura de perfis de solo, e piping encontrado através da utilização do Geo-Radar (GPR), que permitiu sua detecção e correlação com a presença de voçorocas próximas. Evidências de campo permitem assumir que há correlação entre o piping e o início e desenvolvimento de voçorocas e mostram que ele deve ser considerado como um dos processos importantes na gênese desta forma de erosão acelerada.

Palavras chave: piping, voçoroca, latossolos, geo-radar

\begin{abstract}
Tubular voids formed through piping are well studied as features of sub-superficial erosion encountered in several climatic zones. Literature indicates piping as a process associated with gully erosion. This article discusses four (4) different types of pipes observed in the study area in Gouveia, state of Minas Gerais, in a sub-humid tropical region of the brazilian cerrado (savanna) with predominance of latosols, some times related to [of which show close relation with] the presence of gullies. Gullies occur on convex as well as concave slopes developed predominantly on granite-gneiss, basic and metabasic rocks, [which] forming an undulating landscape with long slopes varying from gentle to moderately gentle $\left(5\right.$ to $\left.12^{\circ}\right)$ inclination. Tops are long and relatively flat, maintaining massive types of hill interrupted by no developed hollows and large spurs. Piping was
\end{abstract}


identified in different situations during field works, through the occurrence of pipes, collapsed or not. They differ [one from another] not only in size but also in terms of their location on the slope, soil type and [even] in relation to their position along the gully walls. In this paper the pipes are described and classified on the basis of the existence or not of the tunnel collapse and [regarding] their association with the evolution of the gullies. The collapse generates the occurrence of a superficial channel and enhances the development of gullies. Two situations were detected regarding channels without collapsed: tubular voids found during the opening of soil profile that shows no correlation with the presence of gullies, and tubular voids detected through the use of geo-radar (GPR), what made it possible to establish the association between piping and gullies. Fields evidence permitsto assume that in some circunstances there is a close relationship between piping and gully, showing that piping should be taken into account as an important process involved with the initiation and development of gullies.

Keywords: piping, gully, latosols, geo-radar (GPR)

\section{Introdução}

O reconhecimento de que voçorocas são geradas pela atuação de processos complexos, tem tido respaldo em evidências de campo (Kirkby, 1978; Jones, 1981; Beckedahl \& Dardis, 1988; Bocco, 1991; Poesen et al, 1998; Beavis, 2000). Entre esses processos destaca-se o piping, que constitui um dos tipos mais importantes de erosão subsuperficial do solo (Crouch, 1983; Jones, 1987).

Pierson (1983:1) descreve dutos (pipes) como "tubular voids or passageways in soil that may range in size from narrow conduits only a few millimeters in diameter to tunnels at least many centimeters in diameter". Bull \& Kirkby (1997) atribuem a ocorrência de dutos a fatores tais como: gradiente hidráulico elevado, presença de íons solúveis no solo, ocorrência de períodos de seca prolongados, que favorecem a ocorrência de fissuras, e às chuvas intensas e irregulares que reativam percolações concentradas subsuperficiais. Pierson ainda acrescenta a essa lista vários outros mecanismos como: erosão fluvial sub-superficial, promovida pela ocorrência de olhos d'água (minas) em situações de alto gradiente hidráulico ou baixo poder de agregação do solo, passagens deixadas por raízes decompostas e a ação de escavamento de micro, meso e macro-fauna. Ele também chama a atenção para o fato de que a ocorrência de rocha não alterada, ou de horizontes menos permeáveis, podem induzir à concentração sub-superficial da água levando, eventualmente, à formação desses canais.

Os dutos (pipes) ou túneis se formam a partir do carreamento de pequenos grãos do solo, partículas de argila e outros colóides, ou mesmo através da remoção dos componentes do solo por solução, ou seja, pelo processo de piping. $\mathrm{O}$ transporte desse material se faz através do transporte de sólidos e de componentes dissolvidos em rotas preferenciais, o que lhes confere tanto a atuação de forças físicas, quanto químicas.

O desenvolvimento dessas rotas preferenciais de escoamento sub-superficial pode levar à formação de uma verdadeira rede interligada de fluxos. O surgimento das voçorocas ocorreria com o colapso do teto dos túneis e o alargamento, por escoamento superficial e por movimentos de massa, do canal assim formado. A ação combinada desses processos aumentaria sensivelmente as forças envolvidas na escavação e alargamento das paredes do canal. A atuação desse mecanismo aponta para o fato de que a ocorrência das voçorocas pode envolver processos mais complexos que aqueles resultantes apenas de evolução da incisão de um canal causada pela enxurrada que, após atingir certa profundidade, se transformaria em um canal permanente. Nesse caso, o caráter permanente do canal, considerado pela literatura específica como o elemento morfológico mais importante na definição da forma erosiva -voçoroca- ocorre antes mesmo de incisão por escavamento superficial do fluxo concentrado ao longo de uma calha de escoamento (Bull \& Kirkby, 1997; Bocco, 1991; Young, 1972).

Embora vários autores apontem para a existência de estreita correlação entre a formação das voçorocas e a ação dos piping (Jones, 1987; Beckedahl \& Dardis, 1988), sua comprovação não é fácil, pois nem sempre é possível detectar, na superfície, o início do aparecimento do canal superficial por colapso do túnel. Uma vez ocorrido o colapso, a ação do escoamento superficial tende a se tornar preponderante, encobrindo evidências da presença do duto sub-superficial, anterior à do canal superficial.

Não por acaso, Tanaka et al. (1982) chamam a atenção para o fato de que, devido à extensão da participação do piping no escoamento sub-superficial, pouco ainda se sabe sobre as condições reais de campo envolvidas com o aparecimento de pipes. Beckedahl \& Dardis (1988), por exemplo, apresentam trabalhos nos quais demonstram a estreita relação entre a drenagem artificial e a ocorrência de dutos. Eles atribuem a esta feição antrópica a criação de condições ideais para o aparecimento de piping e voçorocas. Também salientam o papel da vegetação como fator de aumento da infiltração da água de escoamento superficial, o que levaria a erosão por sulcos (seepage). Embora outros trabalhos tenham prosseguido nesta direção, como o de Jones (1987), há questões fundamentais a serem 
respondidas, não só quanto à associação desse processo com o voçorocamento, mas especialmente, a respeito da sua gênese.

Em Gouveia, MG, Brasil, voçorocas são formas comuns de erosão acelerada, ocorrendo principalmente em áreas cujo substrato rochoso é formado por granito-gnaisses, xistos, milonitos e rochas básicas e metabásicas. Também foi detectada a presença de dutos formados por piping, associados em alguns casos, à presença de voçorocas (Augustin et al, 2001). O objetivo desse trabalho é o de apresentar e discutir a ocorrência desses dutos em área de intenso voçorocamento, caracterizada por um clima subúmido e vegetação de cerrado.

$\mathrm{O}$ voçorocamento é entendido aqui, como um conjunto de processos complexos responsáveis pela ocorrência e desenvolvimento de voçoroca, incluindo entre eles a atuação de processos erosivos superficiais concentrados, de movimentos de massa e, eventualmente, a de pipings.

\section{Características Gerais da Área}

Gouveia localiza-se do Estado de Minas Gerais, Brasil, na Serra do Espinhaço Meridional, um cinturão orogênico antigo (Pré-cambriano), que se estende por $1.000 \mathrm{Km}$, de Minas Gerais até o Estado da Bahia. Localmente, a serra é formada por quartzitos do supergrupo Espinhaço e por xistos do supergrupo Rio Paraúna. Estas rochas são cortadas por rochas intrusivas básicas e metabásicas (figura 1).

Topograficamente, os quartzitos e os xistos se encontram em posições mais elevadas, preservados pela erosão diferencial. A erosão atuou predominantemente ao longo dos eixos de anticlinais, provocando, na porção central do município, a exumação do embasamento cristalino granitognáissico, aonde ocorrem os voçorocamentos. O relevo apresenta uma feição levemente escalonada, com as maiores altitudes ocorrendo nos quartzitos (acima de $1.200 \mathrm{~m}$ ), depois nos xistos $(1.200-1.100 \mathrm{~m})$ e finalmente no complexo granítico (900 - $1.100 \mathrm{~m})$, onde se encontram encaixados os canais fluviais dos dois maiores cursos de água do município: ribeirões da Areia e do Chiqueiro.

A Depressão de Gouveia é marcada por um espesso manto de alteração, proveniente da decomposição de granitos-gnaísses, xistos, milonitos, rochas básicas e metabásicas. É nesta área que se concentra a ocorrência de voçorocas, com comprimentos que variam de poucos metros (10m) a centenas de metros $(800 \mathrm{~m})$.

A cobertura vegetal predominante na Depressão é o Cerrado, em graus variados de degradação, desde o cerrado propriamente dito, até o campo sujo. Ao longo dos cursos de água ocorrem matas galerias. O clima é o tropical subúmido, com média anual de precipitação em torno de 1.500 $\mathrm{mm}$, concentrados entre os meses de outubro a março,

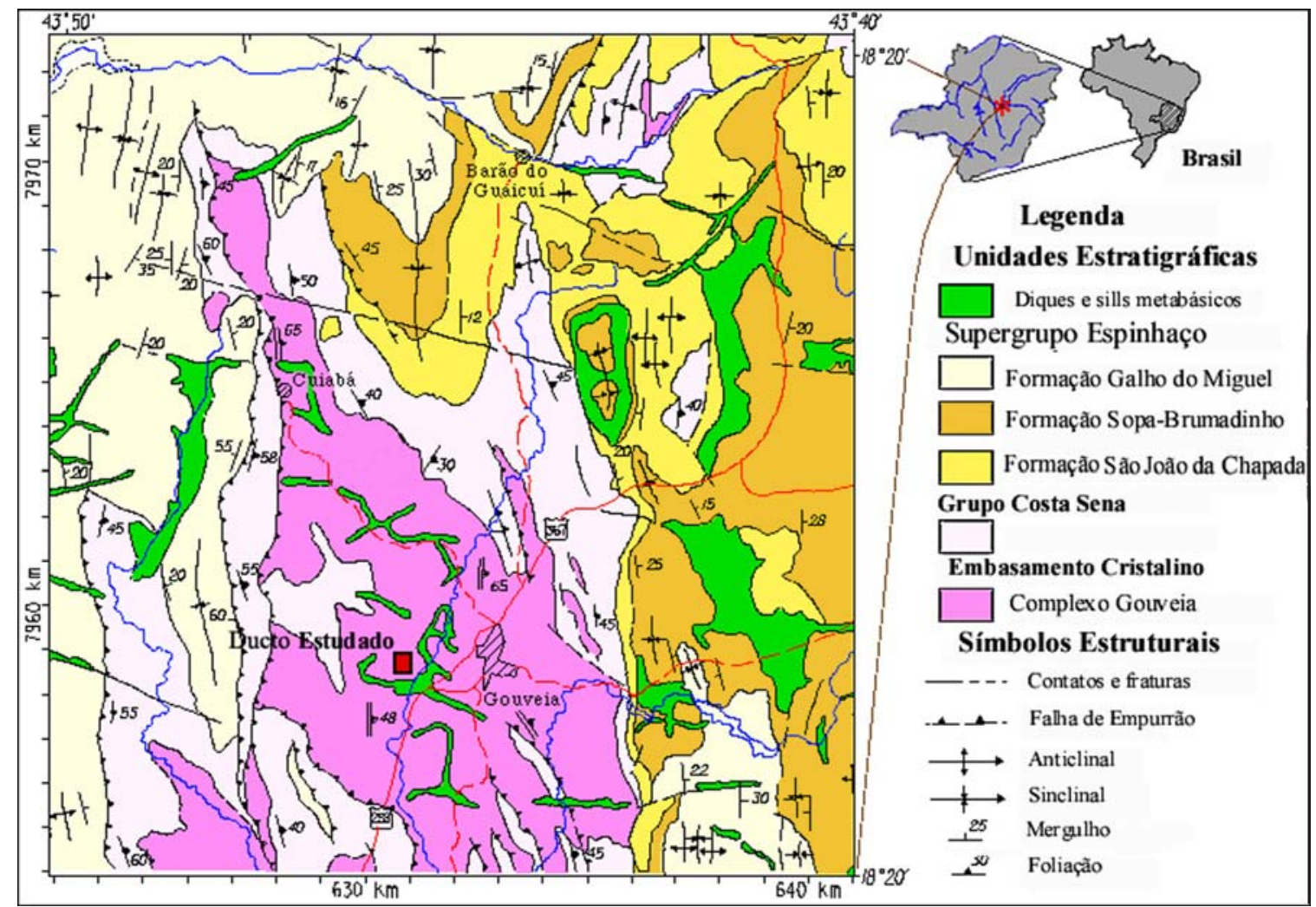

Figura 1 - Localização e mapa geológico da área de estudo, Gouveia, MG. 


\section{Metodologia}

Foram estudadas 27 voçorocas na bacia do ribeirão do Chiqueiro e do Areia, ao longo de etapas distintas de amostragem (Augustin, 1995; Augustin et al., 1999). O levantamento de campo incluiu a coleta de dados de solos ao longo das voçorocas, a cobertura vegetal, a descrição de microformas, as atividades biológicas da mesofauna (formiga e cupins), bem como a utilização de método geofísico para obtenção de dados da sub-superfície, utilizando-se o Radar de Penetração no Solo (Geo-Radar) ou Ground Penetrating Radar $(G P R)$. Durante esses levantamentos foi observada a presença de pipings, às vezes próximos ou interligados à ocorrência de voçorocas.

Para a coleta de dados e descrição dos solos foram abertas 81 trincheiras $(1 \times 1 \times 1,5 \mathrm{~m})$ no ponto central de sítios geomorfológicos (SG), identificados a partir de rupturas de declives. Esses elementos permitem que se assuma a existência de porções da vertente com um certo grau de homogeneidade quanto às suas características internas $\mathrm{e}$ externas, inclusive da atuação de processos, o que os torna funcionais do ponto de vista taxonômico, pois permite a sua utilização para fins de classificação das formas de relevo, levando em consideração também seus atributos (Wright, 1972, 1973, 1977; Augustin, 1997). Para encontrar os SG foram medidos, com auxílio de clinômetro Sunto de leitura direta e de balizas alocadas a intervalos regulares de $10 \mathrm{~m}$, transectos de declividade seguindo a linha de máximo declive (true slope) do topo até a base das vertentes, alinhados a cerca de $10 \mathrm{~m}$ ao lado direito das voçorocas.

Os solos foram descritos no campo de acordo com o manual de campo da Sociedade Brasileira de Ciência do Solo (Kemos e Santos, 1976), incluindo a descrição da cor pelo manual do Munsell Color Chart. Amostras foram coletadas, por horizonte e levadas para análises físico-químicas $(\mathrm{Ca}$, $\mathrm{Mg}, \mathrm{Al}, \mathrm{Fe}, \mathrm{K}, \mathrm{P}, \mathrm{MO}, \mathrm{pH}$, textura) no laboratório da Empresa Brasileira de Pesquisa Agropecuária (EMBRAPA), em Sete Lagoas.

Para um melhor detalhamento da relação entre piping e voçorocas foi realizado o levantamento por Geo-Radar, de uma área localizada em um alvéolo (hollow) ocupado por uma ravina e separado de outro alvéolo por um pequeno esporão onde ocorre a voçoroca 26 , já estudada anteriormente (figura 2). Para se determinar a distribuição dos dutos, foram executados cinco transectos paralelos à drenagem que corre na base da vertente (Augustin et al., 2001). Os transectos cortaram perpendicularmente um dos dutos já em colapso, bem como uma ravina (figura 3 ) e foram dispostos paralelamente entre si, a uma distância regular de 2 (dois) metros, tendo sido, o primeiro deles, alocado mais próximo do canal desmoronado.

Para testar o procedimento que demonstrasse a melhor resposta do Geo-Radar, foi realizado no transecto 3 (central)

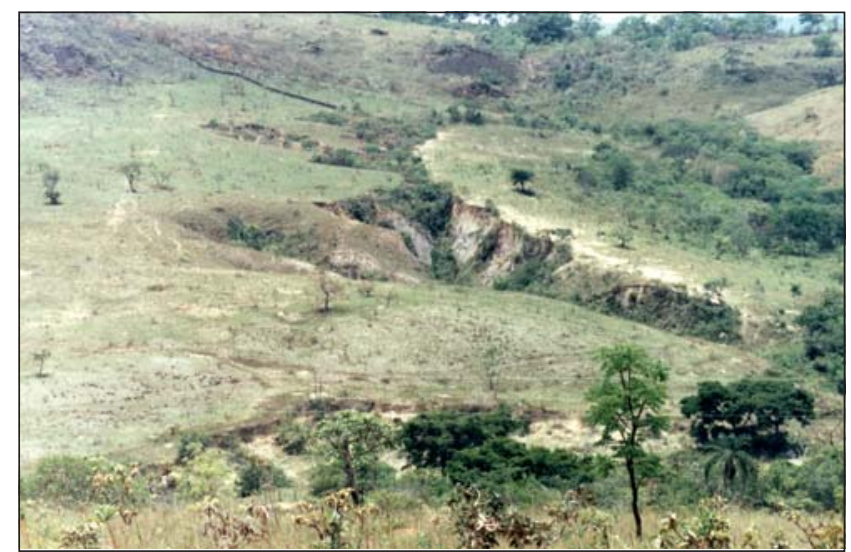

Figura 2 - Voçoroca ${ }^{\circ} 26$ desenvolvida em um alvéolo, mas avançando sobre o esporão à esquerda da vertente. Este conecta-se, por sua vez, com outro alvéolo, no qual detectouse a presença de dutos com colapso parcial do teto. Tanto a voçoroca quanto os dutos desenvolveram-se sobre rochas granito-gnáissicas milonitizadas (Complexo Gouveia).

um teste comparativo com as antenas de 100, 200 e $400 \mathrm{MHz}$. Nele foram também comparadas as variações de respostas da antena de $100 \mathrm{MHz}$ a espaçamento de amostragem de 1,0; 0,50 e $0,25 \mathrm{~m}$. Os melhores resultados foram obtidos com a antena de $100 \mathrm{MHz}$ e com o espaçamento de $0,25 \mathrm{~m}$, procedimentos que foram utilizado para os outros 4 transectos.

\section{Apresentação e Discussão dos Resultados}

Durante o estudo, realizado ao longo de várias etapas de trabalhos de campo, observou-se a existência de quatro tipos principais de dutos aqui denominados de dutos sem colapso; dutos sem colapso, mas associados à presença de voçorocas; dutos com colapso progressivo e dutos com colapso parcial.

\section{- Dutos sem colapso}

Foram encontrados dentro dos horizontes dos solos e detectados durante a abertura de perfis pedológicos (Augustin, 1995). São dutos bem desenvolvidos, com diâmetros em torno de $10 \mathrm{~cm}$, ocorrendo entre 40 e $80 \mathrm{~cm}$ de profundidade. Esses dutos se encontram localizados na alta, na média e na baixa vertente. Ocorrem independentemente do tipo de solo: em latossolos vermelho-escuro, vermelhoamarelo e cambissolos; por isto, os solos não serão descritos ou analisados individualmente, tendo em vista que isto não trará acréscimo de informações. No entanto, esses solos têm em comum várias características entre as quais, estrutura fraca e uma percentagem mais elevada de areia (tabela 1). As cores tendem em geral ao vermelho mais escuro, variando entre 10 YR a 2,5 YR. São solos pobres em bases trocáveis 


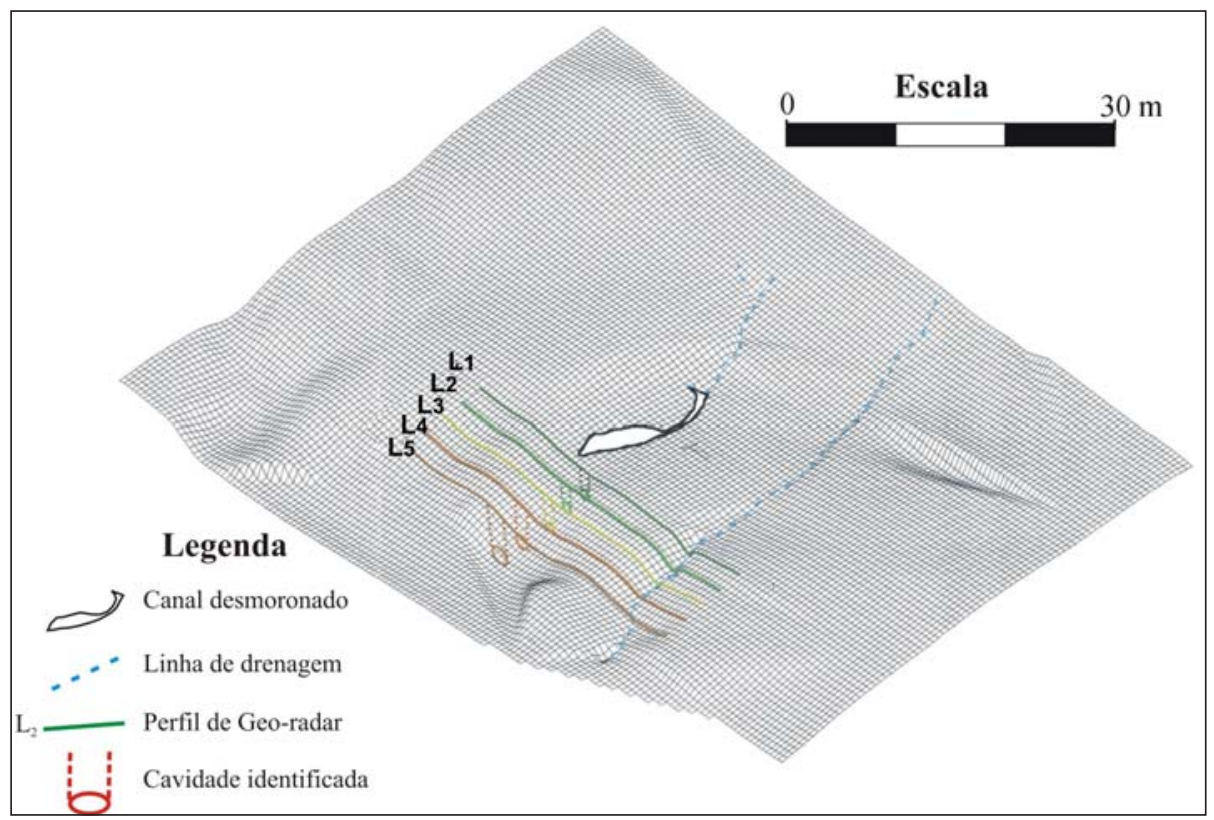

Figura 3 - Modelo tri-dimensional do alvéolo onde ocorre o duto com colapso do teto, sem o desenvolvimento de voçoroca. As linhas de L1 a L5 correspondem aos perfis de GPR executados na área.

Tabela 1. Dados dos perfis de solo, nos quais foram detectados dutos, formados por "piping", sem colapso de teto, Gouveia-MG

\begin{tabular}{|c|c|c|c|c|c|c|c|c|c|c|c|c|c|c|}
\hline \multirow{3}{*}{ 气ै } & \multirow{3}{*}{$\begin{array}{c}\text { Posição } \\
\text { na } \\
\text { Vertente }\end{array}$} & \multirow{3}{*}{$\begin{array}{l}\text { Profun- } \\
\text { didade } \\
\text { (cm) }\end{array}$} & \multicolumn{4}{|c|}{ Textura $(\%)$} & \multirow[t]{3}{*}{$\mathrm{Ca}$} & \multirow{3}{*}{$\begin{array}{l}\mathrm{Mg} \\
\text { Eq.mg }\end{array}$} & \multirow{3}{*}{$\begin{array}{c}\mathrm{P} \\
/ 100 \mathrm{~g}\end{array}$} & \multirow[t]{3}{*}{$\mathrm{K}$} & \multirow[t]{3}{*}{$\mathrm{pH}$} & \multirow[t]{3}{*}{ MO } & \multirow{3}{*}{$\begin{aligned} \mathrm{Fe}_{2} \mathrm{O}_{3} \\
\%\end{aligned}$} & \multirow[t]{3}{*}{ Cor } \\
\hline & & & \multirow[t]{2}{*}{ Argila } & \multirow[t]{2}{*}{ Silte } & \multicolumn{2}{|c|}{ Areia } & & & & & & & & \\
\hline & & & & & Fina & Grossa & & & & & & & & \\
\hline 1 & Alta & $50-70$ & 32 & 22 & 15 & 28 & 0,06 & 0,02 & $<1$ & 19 & 5,3 & 0,65 & 7,83 & 7,5 YR 4/6 \\
\hline 3 & Alta & $80-100$ & 42 & 22 & 17 & 19 & 0,02 & 0,02 & 1 & 11 & 5,5 & 0,53 & 10,54 & $2,5 \mathrm{YR} 4 / 6$ \\
\hline 4 & Meia & $50-80$ & 33 & 27 & 19 & 21 & 0,03 & 0,02 & 1 & 10 & 5,4 & 0,95 & 10,70 & 2,5 YR $4 / 8$ \\
\hline 5 & Baixa & $50-80$ & 42 & 23 & 19 & 16 & 0,06 & 0,03 & 0 & 11 & 5,4 & 1,12 & 11,07 & 2,5 YR $3 / 6$ \\
\hline
\end{tabular}

(Fonte: Augustin, 1995).

(tabela 1), com valores de $C a$ entre 0,01 e 0,06 e de $M g$ entre 0,01 e 0,03 eq.mg/100cc. O $p H$ é ácido $(4,7$ a 5,5$)$ e a porcentagem de matéria orgânica, com exceção de um horizonte, não atingiu $1 \%$, embora tenha sido observada a presença de nódulos orgânicos com até $2 \mathrm{~cm}$ de diâmetro, indicando a existência de atividade biológica em todos os horizontes de todos os solos analisados.
Os valores do alumínio são bastante díspares, não permitindo a identificação de um padrão. O conteúdo de ferro, no entanto, é relativamente elevado, revelando a ocorrência de 2 grupos de solos: um com percentagem entre 7 e 9, e outro entre 10 e $13,5 \%$.

Um dos aspectos mais característicos dos horizontes nos quais se detectou a presença de dutos, é a pouca 
consistência desses solos quando úmidos, que varia de muito friável a solta. É importante destacar que isto ocorre em solos com textura argilosa (41 a 45\% de argila) a franco-argilosa (22 a 35\%). A extrema colapsividade desses solos demonstra que, apesar da grande proporção de argila, eles tendem a se comportar como solos com textura mais de silte e areia fina, em decorrência da aglutinação da fração argila, como demonstrado por Figueiredo et al. (1999).Para testar o procedimento que demonstrasse a melhor resposta do GeoRadar, foi realizado no transecto 3 (central) um teste comparativo com as antenas de 100, 200 e $400 \mathrm{MHz}$. Nele foram também comparadas as variações de respostas da antena de $100 \mathrm{MHz}$ a espaçamento de amostragem de 1,0; 0,50 e $0,25 \mathrm{~m}$. Os melhores resultados foram obtidos com a antena de $100 \mathrm{MHz}$ e com o espaçamento de 0,25 m, procedimentos que foram utilizado para os outros 4 transectos.

São solos, portanto, pobres em bases trocáveis e em percentual de silte (mesmo no caso dos Cambissolos), o que não permite enquadrá-los entre aqueles com características intrínsecas favoráveis ao desenvolvimento de dutos, como descritos por Bull \& Kirkby (1997) e Pierson (1983). A distribuição dos tipos de solos obedece, aproximadamente, sua localização na vertente, com o predomínio de latossolos nos topos e altas vertentes e de cambissolos nas médias e baixas vertentes. Ao longo das vertentes amostradas, não foram observadas rupturas acentuadas de declive, ou aumento de gradiente hidráulico, que pudessem responder pela existência de condições que levassem à iniciação do processo.

A cobertura vegetal de área analisada é bastante homogênea, exceto a que ocorre nos topos, onde é caracterizada por campos limpos, ou nos fundos de vale, por mata galeria. Em comum, esses solos apresentam rocha matriz semelhante, ou seja, são formados a partir da decomposição de rochas básicas e metabásicas, são ricos em ferro e argila, pobres em bases trocáveis e matéria orgânica.

Embora não esteja associado a voçorocas, a ocorrência desse tipo de duto levou ao aparecimento de linhas de depressão superficiais, que favorecem acumulação de água de escoamento e ao desenvolvimento de ravinas (Bull \& Kirkby, 1997). O fato dos tetos dos túneis não apresentarem colapso não tem causas bem definidas, mesmo porque podem ainda atingir o colapso, caso persista a retirada de material fino da sub-superfície.

\section{- Dutos sem colapso, mas associados à presença de voçorocas}

Estes ocorrem ao longo das paredes de todas as voçorocas estudadas, nos mais variados tipos de solos, não permitindo sua associação com algum tipo específico dos mesmos. Esses dutos variam em número, se distribuem por toda parede da voçoroca, atingem diâmetros médios de $10 \mathrm{~cm}$ e ocorrem, em geral, entre 0,40 e $1,5 \mathrm{~m}$ de profundidade.
É possível a distinção desses dutos entre dois sub-tipos: os mais superficiais, que se distribuem entre aqueles que ocorrem próximos a fraturas, o que induz ao aumento da infiltração favorecendo a retirada dos finos; e aqueles com formato bastante arredondado, com diâmetros entre 5 e $10 \mathrm{~cm}$, associados à presença de roedores (figura $4 \mathrm{a}$ ).

Os mais profundos localizam-se, em geral, no contato solo/saprólito; contato este que, em algumas voçorocas, ocorre de forma abrupta. Têm sua gênese, como descrita por Pierson (1983) e Bull \& Kirkby (1997), atribuída à perda de finos provocada pela diferença de velocidade de infiltração entre o solo e o saprólito. Os mais profundos, embora presentes nas paredes de todas as voçorocas, não apresentam evidências de que contribuam para o recuo das paredes por solapamento da base do duto. Observou-se, no entanto, que nos mais superficiais, a tensão hidráulica de saída da água provoca a retirada da porção superior do duto, através da desestabilização do seu teto, levando ao desabamento progressivo do mesmo. Esse processo causa a formação de alcovas, muito semelhantes àquelas formadas pelo efeito da água superficial concentrada quando flui pela parede da voçoroca (figura $4 b$ ).

\section{- Dutos com colapso progressivo}

Este tipo leva à ampliação das ramificações da voçoroca. Nesse tipo de duto o colapso do teto ocorre a certas distâncias do canal principal da voçoroca, em decorrência do piping em direção ao canal da voçoroca. $\mathrm{O}$ colapso se dá ao longo do canal formado pelo fluxo subsuperficial, transformando-o em um canal superficial, que passa a funcionar como uma ramificação (figura 5). Em fases imediatamente posteriores à sua junção com o canal principal, quando a erosão superficial ainda não atuou por tempo suficiente para remodelar o canal, essas ramificações apresentam uma forma anacrônica com relação ao canal principal da voçoroca. À montante, a forma é arborescente, semi-circular, enquanto à jusante, o contato com a voçoroca é realizado por um canal estreito e profundo.

Estão presentes predominantemente nas médias e altas vertentes, em latossolos vermelho-amarelos, em sua maior parte franco-argilosos, com baixa capacidade de troca catiônica, ácidos, pobres em matéria orgânica e com quantidade de ferro variando entre 2,5 a $5 \%$. Ou seja, solos com características muito semelhantes às daqueles nos quais ocorrem os outros tipos de dutos relatados, como exemplificadas na tabela 2. Têm, no entanto, em comum, uma grande percentagem de pedregosidade nas profundidades entre 25 e $50 \mathrm{~cm}$, proveniente da alteração in situ de veios de quartzo leitoso, grosso (com diâmetro variando de 4 a $6 \mathrm{~cm}$ ), angulares e bastante oxidados. Esse tipo de piping pode ser mais comum do que o observado, mas é de difícil identificação, pois não só os dutos, como também os canais colapsados que tendem a abrir-se no contato com o canal principal, são destruídos na medida que ramificação evolui. 


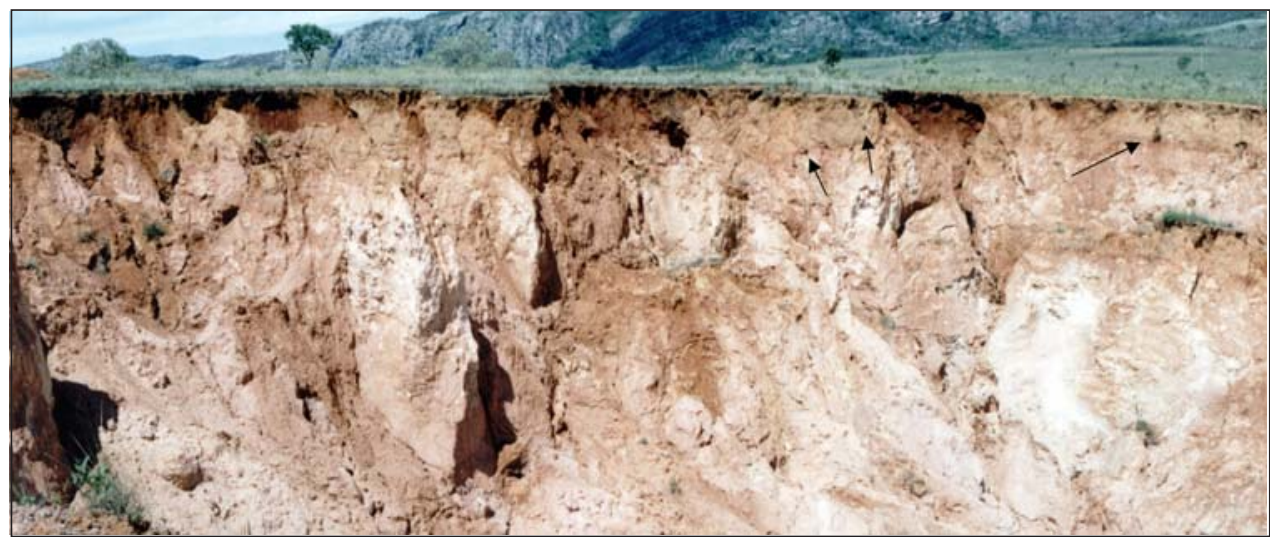

Figura 4a - Dutos mais comuns, encontrados nas paredes de todas as voçorocas estudadas e atribuídos à ação de animais, em especial de roedores.

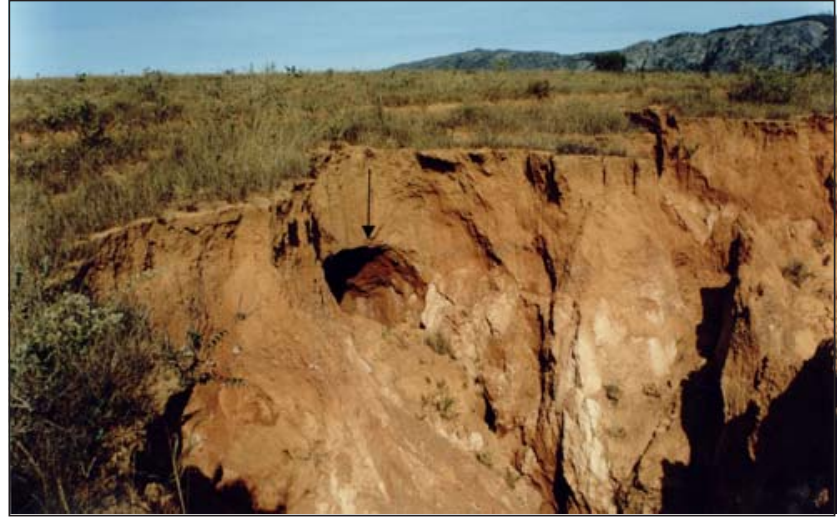

Figura 4b - Duto sem colapso, típico dos latossolos de Gouveia, MG. Este, em especial, apresenta diâmetro acima da média e sinais de colapso por desabamento parcial do teto pelo efeito da enxurrada, formando uma alcova ao longo de uma das paredes de uma voçoroca.

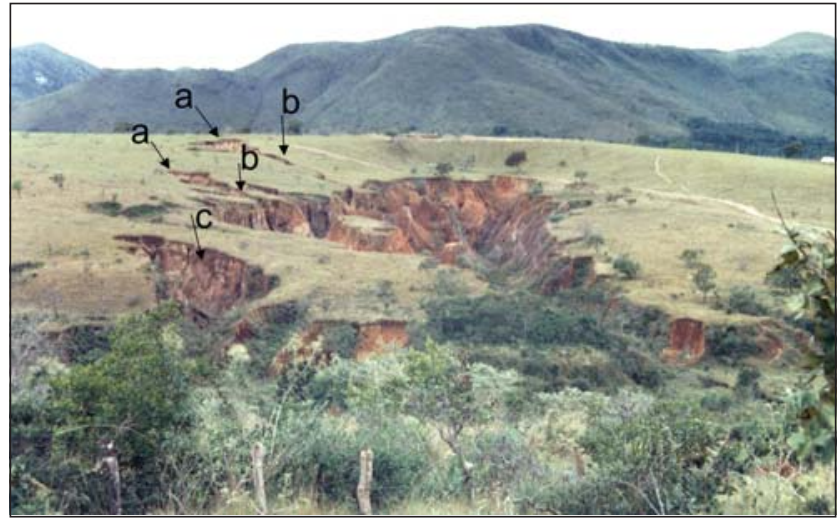

Figura 5 - As ramificações observadas à direita da voçoroca, em especial as duas mais à montante (esquerda da figura), ilustram o tipo de duto "com colapso progressivo" no qual a conexão das ramificações (a) originadas pelo colapso do teto do duto apresenta forma alongada e estreita (b). Já a ramificação indicada pela seta "c" é característica do alargamento produzido pelos deslizamentos nas paredes da voçoroca $(\mathrm{c})$.

Tabela 2. Dados dos perfis de solo, nos quais foram detectados dutos formados por "piping" com colapso de teto, Gouveia-MG

\begin{tabular}{|c|c|c|c|c|c|c|c|c|c|c|c|c|c|c|}
\hline \multirow{3}{*}{$\begin{array}{c}\text { Pon } \\
\text { tos }\end{array}$} & \multirow{3}{*}{$\begin{array}{c}\text { Posição } \\
\text { na } \\
\text { Vertente }\end{array}$} & \multirow{3}{*}{$\begin{array}{l}\text { Profun- } \\
\text { didade } \\
(\mathrm{cm})\end{array}$} & \multicolumn{4}{|c|}{ Textura (\%) } & \multirow[t]{3}{*}{ Ca } & Mg & $\mathbf{P}$ & $\mathbf{K}$ & \multirow{3}{*}{ pH } & MO & $\mathrm{Fe}_{2} \mathrm{O}_{3}$ & \multirow{3}{*}{ Cor } \\
\hline & & & \multirow{2}{*}{ Argila } & \multirow{2}{*}{ Silte } & \multicolumn{2}{|c|}{ Areia } & & \multirow{2}{*}{\multicolumn{3}{|c|}{ Eq.mg/ $100 \mathrm{~g}$}} & & \multirow{2}{*}{\multicolumn{2}{|c|}{$\%$}} & \\
\hline & & & & & Fina & Grossa & & & & & & & & \\
\hline 2 & Alta & $25-50$ & * & * & * & * & * & * & * & * & * & * & * & * \\
\hline 3 & Alta & $50-90$ & 29 & 28 & 18 & 25 & 0,08 & 0,07 & 1 & 21 & 4,8 & 0,97 & 3,19 & $10 \mathrm{YR} 6 / 8$ \\
\hline 4 & Meia & $0-25$ & 26 & 32 & 25 & 17 & 0,06 & 0,06 & 1 & 22 & 4,8 & 1,54 & 4,79 & $10 \mathrm{YR} 5 / 6$ \\
\hline 5 & Meia & $35-40$ & * & $*$ & $*$ & * & * & $*$ & * & $*$ & $*$ & $*$ & $*$ & * \\
\hline 6 & Meia & $40-86$ & 27 & 33 & 22 & 18 & 0,16 & 0,05 & 1 & 15 & 5,0 & 1,04 & 5,03 & $10 \mathrm{YR} 6 / 8$ \\
\hline 7 & Meia & $56-98$ & 32 & 32 & 21 & 15 & 0,07 & 0,01 & 1 & 14 & 5,3 & 0,74 & 5,11 & 5 YR 5/6 \\
\hline 8 & Baixa & $0-38$ & 39 & 24 & 14 & 23 & 0,29 & 0,17 & 2 & 88 & 4,5 & 2,75 & 3,67 & $10 \mathrm{YR} 3 / 3$ \\
\hline
\end{tabular}

- veio de quartzo (Fonte: Augustin, 1995). 


\section{- Dutos com colapso parcial.}

Estes dutos ainda não se desenvolveram em voçorocas e também não se encontram conectados a nenhuma delas (figura 6). Eventualmente, poderão iniciar um processo de expansão por colapso dos tetos, acompanhado de erosão superficial. Ocorrem preferencialmente em porções côncavas da vertente (alvéolos), como o que foi amostrado com o auxílio do Geo-Radar (figura 7), fato este que sugere uma gênese associada ao acúmulo de água nas depressões, aumentando o escoamento superficial e, em decorrência, a infiltração ao longo de linhas preferenciais, em processo semelhante ao descrito por Bull \& Kirkby (1997). Foram identificados também em outras posições nas vertentes, indicando que outros fatores e mecanismos podem estar envolvidos na ocorrência dos mesmos.

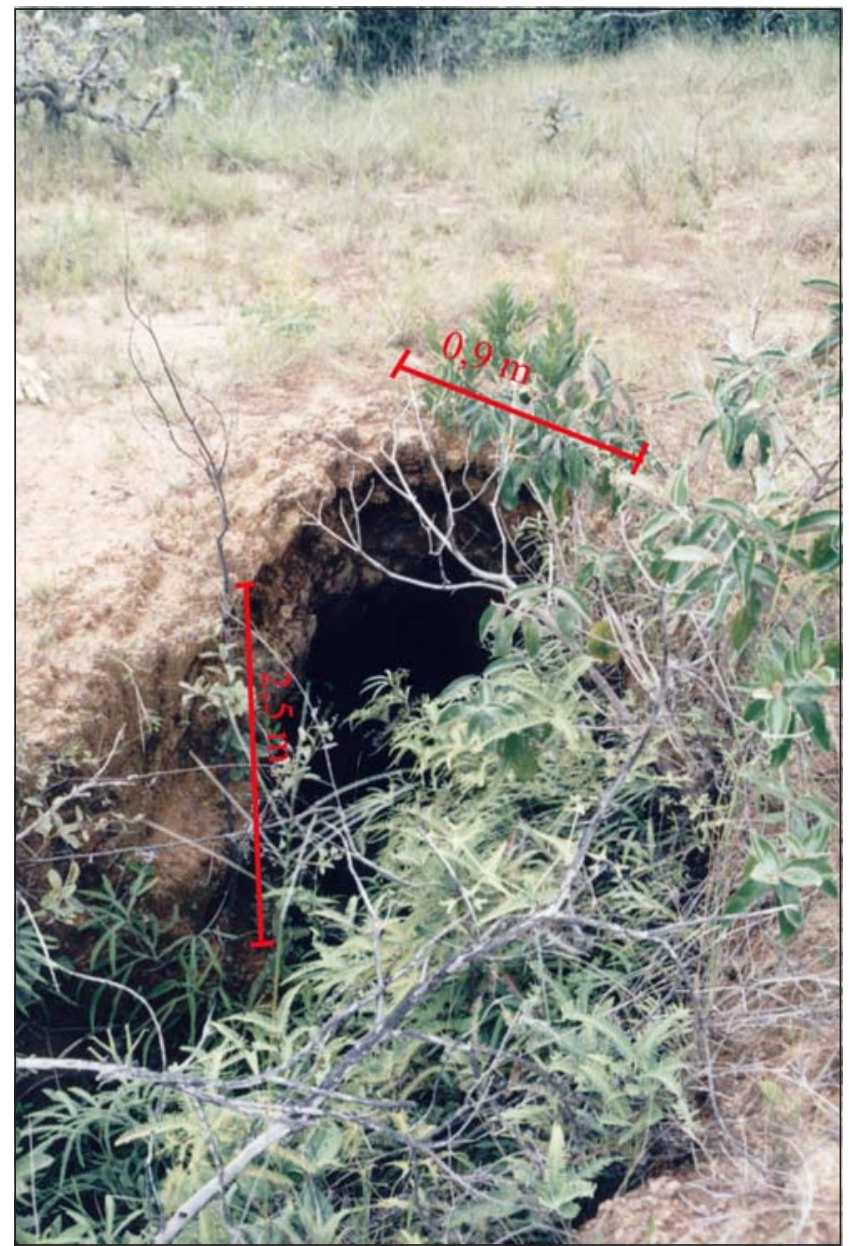

Figura 6 - Dutos apenas com colapso parcial do teto, tendo na parte mais estreita $0,9 \mathrm{~m}$ de largura e uma profundidade de 2,5 m (piso). Este tipo de duto ocorre preferencialmente na média-baixa vertente, em alvéolos, não apresentado colapso total do teto, e, por conseguinte, evidências da escavação do canal por erosão do escoamento superficial concentrado.

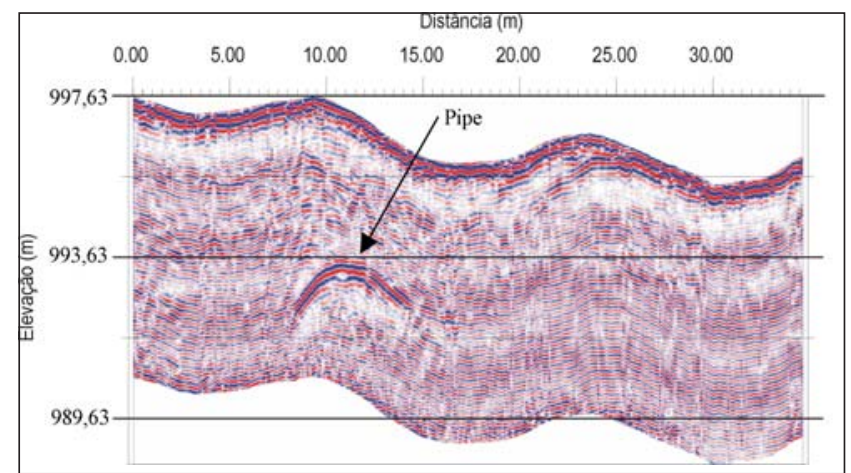

Figura 7 - Radargrama obtido com antenas de $200 \mathrm{MHz}$ ao longo da L3 (mostrada na figura 3), apresentando a reflexão da onda EM na forma de hipérbole sobre a parte superior do pipe.

Estão presentes nos horizontes mais superficiais dos latossolos vermelho-amarelos e de cambissolos, com cores variando entre 7,5YR e 10 YR. Apresentam textura argiloarenosa, com presença relativamente baixa de argila, se comparada àquela encontrada nos outros solos e alto percentual de areia fina. São pobres em bases trocáveis, mas percentualmente contêm mais $C a$ e $M g$ do que solos onde foram detectados outros tipos de dutos. As quantidades de $\mathrm{Ca}$ e $\mathrm{Mg}$ são, contudo, muito baixas para que possam induzirà formação de dutos por dissolução. Apesar de contarem com um $p H$ baixo, entre 4,7 e 5,8, ele é ligeiramente superior, assim como a percentagem de matéria orgânica, ao de outros solo encontrados na área, como pode ser observado na tabela 3.

\section{Conclusão}

Embora haja evidências da participação de piping no processo de voçorocamento, seja através da ocorrência de duto em todas as paredes das voçorocas estudadas, ou próximos a estas, os dados atuais não permitem quantificar, na área, a magnitude e intensidade dessa participação. É possível afirmar, contudo, que os dutos estão associados tanto ao processo de recuo das cabeceiras, quanto ao de alargamento das paredes das voçorocas, bem como a ampliação do número de ramificações, indicando que o piping constitui um dos processos mais importantes na evolução de voçorocas.

Nos casos dos dutos sem ou com colapso do teto, encontrados principalmente nas altas e meias vertentes, o que chama a atenção é a grande colapsividade dos latossolos vermelho-amarelos e vermelho-escuros, no qual ocorrem. São solos com alto teor de argila, mas baixa coesão. Há evidências de que o ferro e/ou do alumínio causem a aglutinação de partículas de argila, o que altera seu comportamento hidrológico, induzindo a uma maior infiltração da água de chuva. Isto aumentaria a pressão hidráulica no interior dos 
Tabela 3. Dados dos perfis de solo, nos quais foram detectados "piping" com colapso de teto, Gouveia/MG

\begin{tabular}{|c|c|c|c|c|c|c|c|c|c|c|c|c|c|}
\hline \multirow{3}{*}{$\begin{array}{l}\text { Ponto } \\
\mathrm{s}\end{array}$} & \multirow{3}{*}{$\begin{array}{l}\text { Posição na } \\
\text { Vertente }\end{array}$} & \multirow{3}{*}{$\begin{array}{l}\text { Profun- } \\
\text { didade } \\
(\mathrm{cm})\end{array}$} & \multicolumn{4}{|c|}{ Textura (\%) } & \multirow[t]{3}{*}{$\mathrm{Ca}$} & \multirow{3}{*}{\multicolumn{2}{|c|}{$\begin{array}{c}\text { Mg P } \\
\text { Eq.mg /100g }\end{array}$}} & \multirow[t]{3}{*}{$\mathbf{K}$} & \multirow[t]{3}{*}{ pH } & \multirow{3}{*}{$\begin{array}{l}\text { мо } \\
(\%)\end{array}$} & \multirow[t]{3}{*}{ Cor } \\
\hline & & & Argila & Silte & \multicolumn{2}{|c|}{ Areia } & & & & & & & \\
\hline & & & & & Fina & Grossa & & & & & & & \\
\hline 1 & Alta & $0-8$ & 23 & 9 & 52 & 16 & 0,20 & 0,25 & 1 & 177 & 5,4 & 1,7 & 7,5 YR $5 / 2$ \\
\hline 2 & Alta & $8-55$ & 25 & 26 & 38 & 11 & 0,05 & 0,05 & 0,5 & 91 & 5,0 & 0,89 & $10 \mathrm{YR} 5 / 4$ \\
\hline 3 & Alta-Média & $0-15$ & 25 & 12 & 51 & 12 & 0,10 & 0,10 & 1,0 & 153 & 5,0 & 1,37 & 10 YR $5 / 4$ \\
\hline 4 & Alta-Média & $15-43$ & 29 & 16 & 44 & 11 & 0,10 & 0,02 & 1,0 & 79 & 4,9 & 1,13 & $\mathrm{~S} / \mathrm{C}$ \\
\hline 5 & Média & $0-10$ & 29 & 19 & 40 & 12 & 0,10 & 0,04 & 1,0 & 112 & 5,8 & 1,21 & $\mathrm{~S} / \mathrm{C}$ \\
\hline 6 & Média & $10-48$ & 35 & 5 & 44 & 16 & 0,15 & 0,02 & 0,5 & 44 & 4,9 & 0,93 & 7,5 YR $6 / 8$ \\
\hline 7 & Baixa & $0-12$ & 24 & 12 & 47 & 17 & 0,20 & 0,03 & 0,0 & 79 & 4,8 & 1,29 & $10 \mathrm{YR} 6 / 3$ \\
\hline 8 & Baixa & $12-66$ & 35 & 16 & 40 & 9 & 0,25 & 0,02 & 0,5 & 44 & 4,7 & 1,00 & $10 \mathrm{YR} 6 / 3$ \\
\hline
\end{tabular}

agregados, destruindo-os e favorecendo o carreamento lento das partículas finas e o surgimento de dutos.

A detecção de dutos pelo Geo-radar (figura 7), com ou sem a ocorrência de colapso do teto, demonstra que o piping pode estar também presente na iniciação do processo. Seus mecanismos, contudo, são ainda pouco compreendidos, embora seja possível se estabelecer relação entre o desenvolvimento dos dutos e a concentração de água subsuperficial nas áreas côncavas e, em casos do colapso do teto, com o desenvolvimento do semi-duto como voçoroca.

\section{Agradecimentos}

À Fundação de Amparo à Pesquisa do Estado de Minas Gerais, FAPEMIG, pelo apoio financeiro (CRA 16995 e CRA 957/01) a esta pesquisa.

\section{Referências Bibliográfica}

Augustin, C.H.R.R.; Aranha, P.R.A.; Timbó-Elmiro et al (2001) A ocorrência de pipes descontínuos em Gouveia, MG, Brasil, detectado com o auxílio do Ground Penetrating Radar (GPR). Anais do XI Congresso Latinoamericano de Geologia, Montevidéu, Uruguai, CDRom; nº 275 (pdf).

Augustin, C.H.R.R.; Aranha, P.R.A., Pires Fo , J.L. et al (1999) Relatório Técnico: Estudo das coberturas superficiais e sua dinâmica cenozóica na região de Gouveia, Espinhaço Meridional. Projeto de Pesquisa, Fundep/Fapemig, CEX 1669-96. 526p. Belo Horizonte.

Augustin, C.H.R.R. (1979) A Preliminary Integrated Survey of the Natural Resources near Alcantarilla, Southeast Spain. MSc Dissertation. University of Sheffield. 209p.
(1995) Geoökologishe Studien im südlichen Espinhaçogebirge bei Gouveia, Brasilien unter besonderer Berücksichtingung der Landschaftsentwicklung. Tese de doutorado, Johann Wolfgang Goethe Universität, Frankfurt a. M., 150p.

Beavis, S.G. (2000) Structural controls on the orientation of erosion gullies in mid-western New South Wales, Australia. Geomorphology, 33 (1-2):59-72.

Beckerdahl, H.R. \& Dardis, G.F. (1988) The role of artificial drainage in the development of soil pipes and gullies: some examples from Transkei, Southern Africa. In Geomorphological Studies in Southern Africa, G.F. Dardis \& B.P. Moon (Eds.), Balkema, Rotterdam.

Bocco, G. (1991) Gully Erosion: Processes and Models. Progress in Physical Geography, v.15(4):392-406.

Bull, L.J. \& Kirkby, M.J. (1997) Gully processes and modelling. Progress in Physical Geography, 21(3): 354-374.

Crouch, R.S. (1983) The role of tunnel erosion in gully head progression. J. Soil Conserv. NSW:145-155.

Dardis, G.F. \& Beckhahl, H.R. (1988) Drainage evolution in a soil pipe-gully system, Transkei, Southern Africa. In Geomorphological Studies in Southern Africa, G.F. Dardis \& B.P. Moon (Eds.), Balkema, Rotterdam.

Diniz, A.D. (2002) Levantamento Pedológico da Porção Norte da Bacia do Ribeirão do Chiqueiro e a Relação entre Classes de Solo e a Erosão, Gouveia, MG. Dissertação de Mestrado, IGC-UFMG, Belo Horizonte, MG.127p.

Figueiredo, M.A.; Augustin, C.H.R.R. \& Fabris, J.D. (1999) Mineralogy, size, morphology and porosity of aggregates and their relationship with soil 
susceptibility to water erosion. Hyperfine Interactions, v.1 (122):177-184.

Jones, J.A.A. (1981) Soil Piping and Stream Channel Iniciation. Water Resources Research, v.7(3):602610.

Jones, J.A.A. (1987) The effects of soil piping on contributing areas and erosion patterns. Earth Surface Processes and Landforms, v.12:229-248.

Kirkby, M.J. (1978) Implications for sediment transport. In Kirkby, M.J. (ed.). Hillslope Hydrology:325-363. Chichester: John Wiley \& Sons Ltd.

Lemos, R. C.; Santos, R. D. Manual de Descrição e Coleta de Solo no Campo. 2.ed. Campinas, Sociedade Brasileira de Ciências do Solo, 1976, 45p

Pierson, T.C. (1983) Soil pipes and slope stability. Q. J. Eng. Geol., v.16:1-11.

Poesen, J.; VANDAELE, K. \& WESEMAEL, B.(1998) Gully erosion: importance and model implications. NATO ASI Series, vol. I: 55p.
Quintero, L.F.O. (1999) Diagnóstico Ambiental da Bacia do Ribeirão do Chiqueiro, Município de Gouveia, MG: Uma abordagem a partir da Ecologia da Paisagem. Dissertação de Mestrado Instituto de Geociências, Universidade Federal de Minas. Belo Horizonte. 136p.

Tanaka, T.; Yasuhara, M. \& Marui, A. (1982) Pulsating flow phenomenon in pipe. Ann. Rep. Geosci. Univ. Tsukuba, ${ }^{\circ}$ 8:33-36.

Wright, R.L. (1972) Principals in Geomorphological Approach to Land Classification. Zeichsfr Geomorph. 16:351373.

(1973) An Examination of the value of site analysis in field studies in tropical Australia. Zeitchsfr. Geomorph. 17:157-183.

(1977) On the Application of Numerical Taxonomy in Soil Classification for Land Evaluation. ITC Journal 21:482-509.

Young, A. (1972): Slopes. Logman. Londres.160p. 